\title{
Estrutura de Custos das Empresas do Setor de Vestuário Listadas na Bovespa: Utilização da Análise de Regressão Linear
}

\author{
Adriana Kroenke \\ Mestrado em Ciências Contábeis pela Universidade Regional de Blumenau - FURB \\ Rua Antônio da Veiga, 140. Victor Konder. Blumenau/SC \\ E-mail: didlen@terra.com.br
}

\begin{abstract}
Ari Söthe
Mestrado em Ciências Contábeis pela Fundação Universidade Regional de Blumenau -

FURB

Rua Antônio da Veiga, 140. Victor Konder. Blumenau/SC E-mail:ari_sothe@yahoo.com.br

Jorge Eduardo Scarpin Doutorado em Controladoria e Contabilidade pela Universidade de São Paulo - USP Professor da Fundação Universidade Regional de Blumenau - FURB Rua Antônio da Veiga, 140. Victor Konder. Blumenau/SC E-mail: jorgescarpin@furb.br
\end{abstract}

\section{RESUMO}

A estrutura de custos é fundamental para o gerenciamento de empresas de todos os setores e portes, pois possibilita um melhor acompanhamento do desempenho econômico e auxilia na tomada de decisão. As empresas do setor de vestuário que possuem uma rotatividade de processos bastante diversificada necessitam de um acompanhamento contínuo e rigoroso dos custos de cada operação, bem como a identificação dos custos fixos e variáveis de cada produto. O objetivo deste estudo é verificar a estrutura de custos das empresas do setor de vestuário listadas na Bovespa, com a utilização da análise de regressão linear. Para tal, foram coletados dados trimestrais do lucro líquido, receita líquida e resultado operacional das três empresas do setor de vestuário listadas na Bovespa. Nesse sentido, esta pesquisa caracteriza-se como descritiva, documental, com abordagem quantitativa. Os dados foram coletados no sítio da Bovespa e analisados por meio da aplicação da análise de regressão linear. Quanto aos resultados verifica-se que: a Botucatu Têxtil SA apresenta custos e despesas fixas superiores e custos e despesas variáveis inferiores; a Marisol SA apresenta custos e despesas variáveis superiores aos custos e despesas fixas. A margem de contribuição das empresas não apresenta diferença significativa. Apesar das três empresas analisadas serem do mesmo ramo e de capital aberto, a estrutura de custos apresenta uma diferença considerável nos custos e despesas fixas e custos e despesas variáveis.

Palavras-chave: Setor vestuário. Estrutura de custos. Análise de regressão linear. 


\section{Cost Structure of the Clothing Sector Companies Listed in Bovespa Using Linear Regression Analysis}

\section{ABSTRACT}

The cost structure is fundamental to the management companies of all sectors and sizes, it allows for better monitoring of economic performance and assists in decision making. The companies in the clothing industry that have a turnover of diversified processes require a continuous and rigorous monitoring of the costs of each operation and the identification of fixed and variable costs of each product. The goal is to study the cost structure of companies in the garment sector listed on Bovespa, with the use of linear regression analysis. To this end, data were collected quarterly net profit, net income and operating income of the three companies in the clothing listed at Bovespa. In that sense, this research is characterized as descriptive, documentary, using a quantitative approach. Data were collected at the site of Bovespa and analyzed by applying the linear regression analysis. As for the results it appears that: Botucatu Textil SA has fixed costs and expenses and higher costs and lower variable costs, Marisol SA presents costs and variable costs exceed the costs and fixed expenses. The contribution margin business has no significant difference. Although the three companies examined are of the same branch and open capital cost structure presents a considerable difference in costs and expenses and fixed costs and variable expenses.

Keywords: Clothing Industry. Cost structure. Linear regression analysis.

\section{INTRODUÇÃO}

O sucesso de uma empresa está ligado a vários fatores, entre eles, na constante preocupação em controlar os custos. Esse controle é válido e necessário tanto para empresas de grande porte, quanto para empresas de pequeno porte. Os custos de uma determinada empresa dependem, por exemplo, do setor, ramo de atuação e porte, porém, independente do ramo de atuação empresarial e posicionamento no mercado, é importante que as organizações tenham um gerenciamento de custos que possibilite analisá-las como um todo e cada parte individualmente. Essa análise permite verificar a sua situação financeira, bem como avaliar os métodos utilizados para atingir a rentabilidade objetivada.

Uma estrutura de custos necessita diferenciar os custos fixos e variáveis de modo que a margem de contribuição de cada produto a ser vendido possa ser analisada de forma crítica possibilitando um aumento significativo na receita da 
Estrutura de Custos das Empresas do Setor de Vestuário Listadas na Bovespa: Utilização da Análise de Regressão Linear Adriana Kroenke, Ari Söthe, Jorge Eduardo Scarpin

empresa. Horngren et al. (2000, p. 2) apontam que "a contabilidade de custos mensura e relata informações financeiras e não-financeiras relacionadas à aquisição e ao consumo de recursos pela organização". Os autores destacam ainda que estas informações são fornecidas tanto para a contabilidade gerencial quanto para a financeira. De acordo com Maher (2001, p. 40), os "contadores de custos devem constantemente analisar operações e custos para identificar como as operações e a qualidade dos produtos podem ser melhoradas, ao tempo em que os custos são reduzidos".

Para que os contadores possam analisar operações e oferecer estas informações aos gestores possibilitando efetivamente melhorar os processos de produção e reduzir os custos do produto, são necessárias algumas medidas de controle de custos, estruturados de modo que atendam os objetivos dos gestores quanto às informações necessárias para as tomadas de decisão.

"Já no processo decisório, a contabilidade de custos é capaz de promover a eficiência e a eficácia organizacional, permitindo a tomada de ações corretivas quando necessário, ajudando a empresa a manter-se competitiva no mercado e conduzindo-a a continuidade" (ALBANEZ et al., 2007, p. 8).

Gorini (2000) relata que o Brasil está entre os dez maiores produtores mundiais do setor têxtil englobando a produção de fios, tecidos e malhas, especialmente de algodão. Afirma que no segmento malhas com predominância de algodão, o país é o terceiro maior produtor mundial, ficando somente atrás dos Estados Unidos e da Índia. Nas empresas do setor de vestuário, os custos com a produção das peças é parte fundamental para que se possa analisar a sua situação financeira. Para controlar estes gastos de modo a maximizar o lucro ou a margem de contribuição, a contabilidade de custos assume uma posição indispensável considerando que é necessário ter uma estrutura de custos que consiga gerenciar e fornecer informações a respeito deste processo.

Deste modo, a questão de pesquisa a ser investigada é: qual a estrutura de custos das empresas do setor de vestuário listadas na Bovespa? O objetivo deste 
estudo consiste em verificar a estrutura de custos das empresas do setor de vestuário listadas na Bovespa, com a utilização da análise de regressão linear.

A utilização da análise de regressão linear se justifica pelo fato de que a Demonstração do Resultado do Exercício - DRE não apresenta a separação dos custos fixos e variáveis, indispensável para que se consiga obter a margem de contribuição da empresa permitindo verificar o impacto nos resultados das variações nas quantidades vendidas, custos variáveis ou preços unitários de venda. O setor vestuário, de acordo com Goularti Filho e Jenoveva Neto (1997, p. 105), "propicia o desenvolvimento em conjunto de outras atividades, pelo seu efeito multiplicador, especialmente para 0 comércio e serviços".

O presente artigo está estruturado em cinco seções, iniciando com a presente introdução. A segunda seção apresenta a fundamentação teórica que discorre sobre o custeio variável ou direto, custeio por absorção, custeio baseado em atividades e contabilidade de custos no setor de vestuário. A terceira seção apresenta o método e procedimentos da pesquisa e na quarta seção apresenta-se a descrição e análise dos dados. Em seguida, na quinta seção, são apresentadas as conclusões da pesquisa.

\section{FUNDAMENTAÇÃO TEÓRICA}

\subsection{Custeio Variável ou Direto}

Garrison e Noreen (2001) afirmam que o custeio variável pode ser denominado de custeio direto ou custeio marginal. De acordo com os autores, o termo custeio direto que foi muito utilizada durante muito tempo está desaparecendo no dia-a-dia.

O custeio variável ou custeio direto é um dos diversos sistemas de contabilização dos custos, sendo definido por Maher (2001, p. 360) como "sistema de contabilização de custos em que apenas os custos variáveis de produção são atribuídos aos produtos". Nesta metodologia os custos variáveis são os formadores dos custos dos produtos e os custos fixos totais são considerados como despesas do exercício.

Corroborando Hansen e Mowen (2001, p. 668) destacam que o custeio variável "atribui apenas os custos variáveis de manufatura em um nível de unidade ao produto; 
esses custos incluem os materiais diretos, a mão-de-obra direta e os CIF variáveis". Cada unidade dos produtos incorporará assim somente os custos variáveis unitários, sendo os custos fixos contabilizados como despesas do exercício, sem incorporar os produtos no estoque. A destinação dos custos fixos diretamente ao resultado como despesas do período, reduzirá os custos de fábrica estocáveis, ou seja, no custeio variável, somente os materiais diretos, a mão-de-obra direta e os custos indiretos de fabricação (CIF) variáveis serão estocados (HANSEN; MOWEN, 2001).

Horngren et al. (2000, p. 211) apresentam o custeio variável com "o método de custeio de estoque em que todos os custos de fabricação variáveis são considerados custos inventariáveis. Todos os custos de fabricação fixos são excluídos dos custos inventariáveis: eles são custos do período em que ocorreram". Por serem considerados custos da estrutura, diversos autores entendem que os custos fixos devam figurar como custos do período em que ocorrem independentemente da fabricação ou não dos produtos.

Os custos fixos podem ser definidos como os "custos que não se alteram quando o volume se altera dentro de um intervalo relevante de atividade" (MAHER, 2001, p. 75). Este conceito é compreendido, considerando-se que o custo fixo da empresa não varia em função dos volumes produzidos nos períodos, ou seja, a relação direta do volume de produção e custo fixo não existe. As alterações nos custos fixos ocorrem independentemente do volume produzido dentro de determinada estrutura de produção.

Oliveira et al. (2006) classificam como custos variáveis todos os custos diretos e alguns custos indiretos. São classificados como custos diretos aqueles diretamente envolvidos na produção de um bem ou serviço e os custos indiretos são os custos necessários à produção e de difícil atribuição de determinada parcela a cada produto.

No que diz respeito à Demonstração de Resultado, Stoffel (2007, p. 8) afirma que "baseia-se no modelo de margem de contribuição, sendo assim, o lucro operacional apurado é influenciado por variações nos níveis unitários das vendas".

Maher (2001) apresenta a margem de contribuição como a diferença entre receitas e custos variáveis, ou como preço menos o custo variável unitário, multiplicado pela quantidade produzida e efetivamente vendida. Destaca Maher (2001, p. 433) que 
Estrutura de Custos das Empresas do Setor de Vestuário Listadas na Bovespa: Utilização da Análise de Regressão Linear Adriana Kroenke, Ari Söthe, Jorge Eduardo Scarpin

"é a quantia com que as unidades vendidas contribuem para cobrir os custos fixos e gerar lucro operacional".

No setor industrial, de acordo com Horngren et al. (2000, p. 52), "as duas áreas de diferença entre a margem de contribuição e a margem bruta são: os custos fixos de produção e as despesas variáveis". Os autores destacam que ao calcular a margem de contribuição os custos fixos não são deduzidos da receita.

A estrutura da Demonstração de Resultados por meio do custeio variável é elaborada de uma forma diferente da Demonstração de Resultado do custeio por absorção (HANSEN; MOWEN, 2001).

\begin{tabular}{|c|}
\hline Demonstração de Resultado do Custeio Variável \\
\hline Vendas \\
Menos: Despesas variáveis \\
Margem de contribuição \\
Menos: CIF fixos da fábrica \\
Despesas fixas de marketing e administrativas \\
Resultado Operacional \\
\hline
\end{tabular}

Quadro 1: Estrutura da demonstração de resultado - custeio variável

Fonte: Adaptado de Hansen e Mowen (2001).

As diferentes metodologias para a elaboração da Demonstração de Resultados proporcionarão distintas informações aos usuários. Neste trabalho foram utilizadas as informações proporcionadas pela metodologia do custeio variável.

No aspecto decisorial, o custeio variável gera informações fundamentais para a empresa de forma mais rápida. O seu resultado medido parece ser mais informativo à administração, por abandonar os custos fixos e tratá-los como despesas (MARTINS, 2003). É importante destacar que os princípios contábeis não permitem a elaboração da Demonstração de Resultados avaliada com base no custeio variável (MARTINS, 2003), o que não impede que seja utilizada para fins gerenciais.

\subsection{Custeio por Absorção}

Para Garrison e Noreen (2001, p. 196), "o custeio por absorção atribui parte do custo indireto de fabricação fixo a cada unidade do produto, juntamente com os custos de fabricação variáveis". Stoffel $(2007$, p. 7$)$ afirma que "neste método por meio das 
contas naturais das despesas de fabricação, faz-se a transferência direta para os produtos por meio do emprego de um critério de rateio baseado em alguma medida de volume".

O custeio por absorção é aceito pela legislação fiscal pelo fato de sua aplicação ser derivada dos princípios contábeis, fazendo com que esta metodologia não consiga atender totalmente as novas funções de controle e decisão que os custos podem proporcionar (SOARES et al., 2007).

Uma desvantagem da utilização do custeio por absorção, destacada por Maher (2001, p. 374), é que "os custos fixos são tratados como se fossem custos unitários" podendo provocar enganos ao avaliar o desempenho ou até no momento de tomar decisões. Como uma das vantagens ele destaca que a implantação do método pode ser mais barata pelo fato de não exigir a separação dos custos dos produtos em fixos e variáveis.

No Quadro 2 pode-se verificar a estrutura da demonstração de resultados por meio do custeio por absorção segundo Hansen e Mowen (2001).

\begin{tabular}{|c|}
\hline Demonstração de Resultado do Custeio por Absorção \\
\hline Vendas \\
Menos: Custo de produtos vendidos \\
Lucro bruto \\
Menos: Despesas variáveis de marketing \\
Despesas fixas de marketing e administrativas \\
Resultado operacional \\
\hline
\end{tabular}

Quadro 2: Estrutura da demonstração de resultado - custeio por absorção

Fonte: Adaptado de Hansen e Mowen (2001).

\subsection{Custeio Baseado em Atividades}

$O$ custeio baseado em atividades (activity-based costing - $A B C$ ), segundo Garrison e Noreen (2001), é um método de custeio utilizado como um elemento da gestão por atividade, ou seja, ele possui seu foco nas atividades. "É um método de custeio projetado para municiar os gerentes com informações de custo, para decisões estratégicas ou de outra natureza, que potencialmente afetem a capacidade e, por conseguinte, os custos "fixos"' (GARRISON; NOREEN, 2001, p. 223). 
Segundo Stoffel (2007), o custeio baseado em atividades é muito eficiente por ser um dos métodos que menos distorcem informações de custos, o que consequentemente traz informações mais exatas auxiliando a tomada de decisão e facilitando o trabalho dos gestores para identificar custos relevantes.

Diehl et al. (2008) destacam que o método ABC objetiva identificar por meio de rastreamento a causa dos custos para então alocá-los aos objetos, diferente dos demais métodos que o fazem por rateio, sendo o $A B C$ recomendado para organizações que tenham linha de produção diversificada ou alta parcela de custos indiretos. $O A B C$, segundo Martins (2003, p. 87), "não se limita ao custeio de produtos. Ele é, acima de tudo, uma poderosa ferramenta a ser utilizada na gestão de custos".

Em suma, conforme destaca Maher (2001), este método consiste em atribuir custos aos produtos baseando-se no conjunto de atividades necessárias para fabricação dos mesmos como, por exemplo, testes de qualidade, reparo de máquinas, engenharia de produtos e distribuição aos clientes.

\subsection{Contabilidade de Custos no Setor de Vestuário}

A indústria do vestuário compreende a produção de diversos produtos. Não há um produto padrão onde as operações, o tempo de produção e o nível de dificuldade são os mesmos. Goularti Filho e Jenoveva Neto (1997) afirmam que na indústria de confecção do vestuário existe um grande número de produtos heterogêneos com destino a usos diferenciados. Algumas indústrias do vestuário são de artigos básicos e outras destinadas à produção de artigos da moda.

Lima (1999) afirma que apesar dos avanços tecnológicos nas plantas industriais, o setor de vestuário mantém seu caráter descontínuo com gargalos de produção no acabamento das peças, e para tal continuam utilizando as máquinas de costura que não dispensam seus operadores.

Strumiello (1999, p. 82) afirma que, a exemplo de outros setores, no setor de vestuário "o controle de custos é fundamental, pois a partir dele que são obtidas as informações referentes aos custos dos produtos, o que certamente é imprescindível na formação do preço". 
Kaspczak e Scandelari (2007) pesquisaram a respeito da utilização das informações de custos por indústrias de confecção da cidade de Ponta Grossa e constataram que a maioria delas não utiliza informações de custos com o objetivo de otimizar resultados, melhorar os processos e principalmente para controlar e reduzir custos. A maioria das empresas utiliza as informações de custos que possuem, basicamente para formação de preço de venda de seus produtos e, algumas as utilizam para controlar e reduzir seu nível de custos.

Hall et al. (2008) realizaram uma pesquisa com micro e pequenas empresas de vestuário de Dourados/MS com o intuito de verificar o grau de conhecimento e utilização das ferramentas contábeis para tomada de decisões. Constataram que estas empresas utilizam a contabilidade somente para atender as obrigações fiscais, de modo algum para auxiliar na tomada de decisão e informações que levem a melhorar os resultados.

\section{MÉTODO E PROCEDIMENTOS DA PESQUISA}

Quanto ao objetivo esta pesquisa classifica-se como descritiva. Para Raupp e Beuren (2004, p. 81), "a pesquisa descritiva configura-se como um estudo intermediário entre a pesquisa exploratória e a explicativa, ou seja, não é tão preliminar como a primeira e não tão aprofundada como a segunda. Nesse contexto, descrever significa identificar, relatar, comparar, entre outros".

Para realizar esta pesquisa decidiu-se utilizar as empresas do setor de vestuário listadas na Bovespa. O setor de vestuário diferencia-se da indústria têxtil, pois, conforme Rolim (1997), na indústria têxtil o processo inicia na porta da fábrica com os fardos de algodão e na indústria de vestuário o processo inicia com a compra de peças de tecido produzidas pela indústria têxtil. O setor de vestuário, portanto, exclui as empresas de fiação e tecidos.

A coleta dos dados foi obtida em demonstrações contábeis divulgadas no sítio da Bovespa, classificando a pesquisa como documental em relação aos procedimentos utilizados. De acordo com Beuren (2006, p. 90), as pesquisas documentais são 
Estrutura de Custos das Empresas do Setor de Vestuário Listadas na Bovespa: Utilização da Análise de Regressão Linear Adriana Kroenke, Ari Söthe, Jorge Eduardo Scarpin

utilizadas na Contabilidade quando se quer "analisar o comportamento de determinado setor da economia, como os aspectos relacionados à situação patrimonial, econômica e financeira".

Os dados foram analisados por meio da aplicação da técnica de regressão linear simples com utilização do software SPSS para verificar a estrutura de custos das três empresas listadas na Bovespa. Nesse sentido, quanto à abordagem, a pesquisa se classifica como quantitativa. Para Beuren (2006, p. 92) "esse procedimento não é tão profundo na busca do conhecimento da realidade dos fenômenos, uma vez que se preocupa com o comportamento geral dos acontecimentos".

A Análise de Regressão Linear "consiste em determinar uma função matemática que busca descrever o comportamento de determinada variável, denominada dependente, com base nos valores de uma ou mais variáveis, denominadas independentes" (CUNHA; COELHO, 2007, p. 132). Desta forma, segundo Hair (2005, p. 137), tem por objetivo "prever uma única variável dependente a partir do conhecimento de uma ou mais variáveis independentes". Quando o problema envolver uma única variável independente a técnica é denominada como análise regressão simples e, quando envolver duas ou mais variáveis independentes, a técnica passa a ser denominada análise de regressão múltipla.

Portanto, conforme destacam Cunha e Coelho (2007), essa técnica pode ser compreendida como sendo o estabelecimento de uma relação funcional entre duas ou mais variáveis envolvidas com o intuito de descrever algum fenômeno.

O modelo de regressão linear simples é apresentado na fórmula:

$$
\hat{\mathrm{Y}}=\beta_{0}+\beta_{1} \mathrm{X}_{1}+\varepsilon
$$

Onde, $\beta_{i}$ são os coeficientes de regressão e $\varepsilon$ o erro ou então resíduos da equação.

Nesta pesquisa considera-se o seguinte modelo de regressão linear simples: 


$$
\mathrm{LL}=\text { Constante }+\beta * \mathrm{ROL} \text {, onde: }
$$

$\mathrm{LL}=$ Lucro Líquido

$\mathrm{ROL}=$ Receita Operacional Líquida.

Sabe-se que: $\mathrm{LL}=\mathrm{ROL}-\mathrm{CDV}-\mathrm{CDF}(1)$ ou $\mathrm{LL}=\mathrm{ROL} * \mathrm{MC} \%$ - $\mathrm{CDF}$, onde:

$\mathrm{LL}=$ Lucro Líquido

$\mathrm{ROL}=$ Receita Operacional Líquida

$\mathrm{CDV}=$ Custos e Despesas Variáveis

$\mathrm{CDF}=$ Custos e Despesas Fixas

$M C=$ Margem de Contribuição

Martins (2003, p. 179) define a margem de contribuição por unidade como "a diferença entre o preço de venda e o custo variável de cada produto; é o valor que cada unidade efetivamente traz à empresa de sobra entre sua receita e o custo que de fato provocou e que the pode ser imputada sem erro".

Considerando que a Constante $=-$ CDF e $\beta=\mathrm{MC} \%$ e, ainda, que a margem de contribuição é obtida pela fórmula abaixo:

$$
\mathrm{MC} \%=1-\frac{\mathrm{CDV}}{\mathrm{ROL}}(\mathbf{2}) \quad \text { tem-se: } \quad \beta=1-\frac{\mathrm{CDV}}{\mathrm{ROL}}
$$

De acordo com Warren et al. (2003), a margem de lucro neste estudo tratada como margem líquida é a proporção entre o lucro operacional e as vendas. A margem líquida é obtida pelo quociente:

$$
\mathrm{ML}=\frac{\mathrm{LL}}{\mathrm{ROL}}
$$

E o lucro líquido é representado pela equação (1). Dividindo esta equação pela Receita Operacional Líquida tem-se: 


$$
\frac{\mathrm{LL}}{\mathrm{ROL}}=\frac{\mathrm{ROL}}{\mathrm{ROL}}-\frac{\mathrm{CDV}}{\mathrm{ROL}}-\frac{\mathrm{CDF}}{\mathrm{ROL}},(4)
$$

Substituindo (3) em (4), tem-se:

$$
\mathrm{ML}=1-\frac{\mathrm{CDV}}{\mathrm{ROL}}-\frac{\mathrm{CDF}}{\mathrm{ROL}}
$$

Assim, substituindo (2) em (5):

$$
\mathrm{ML}=\mathrm{MC} \%-\frac{\mathrm{CDF}}{\mathrm{ROL}}
$$

ou,

$$
\mathrm{CDF} \% \mathrm{ROL}=\mathrm{MC} \%-\mathrm{ML}
$$

Logo, como MC\% = $\beta$ chega-se a equação:

$$
\mathrm{CDF} \% \mathrm{ROL}=\beta-\mathrm{ML}(6)
$$

\section{DESCRIÇÃO E ANÁLISE DOS DADOS}

Para aplicar o modelo apresentado na seção 3, é necessário que se conheça a Margem Líquida Média das empresas analisadas. Para tal, aplicou-se inicialmente a fórmula (3) nos dados coletados de cada uma das empresas, obtendo os resultados da Tabela 1.

Tabela 1 - Margem Líquida Média das empresas analisadas

\begin{tabular}{|c|c|}
\hline Empresas & Margem Líquida \\
\hline BOTUCATU TÊXTIL SA & $-0,12327$ \\
\hline CIA HERING & 0,045434 \\
\hline MARISOL SA & 0,076952 \\
\hline
\end{tabular}

Fonte: dados da pesquisa. 
Pelos dados apresentados na Tabela 1, observa-se que a Marisol SA apresenta a maior margem líquida média dentre as empresas analisadas. Esses dados foram utilizados para estimar o percentual de Custos e Despesas Fixas, bem como o percentual de Custos e Despesas Variáveis a fim de obter a estrutura de custos das três empresas analisadas.

\subsection{Botucatu Têxtil S/A}

Para estimar a estrutura de custos verificou-se primeiramente a relação entre o Lucro Líquido e a Receita Líquida da empresa, por meio da regressão linear simples considerando o Lucro Líquido (LL) como variável dependente e a Receita Líquida ( $R L$ ) como variável independente. Com isso foi possível obter o coeficiente necessário para aplicar o modelo proposto. Na Tabela 2 apresenta-se o resumo dos resultados da análise de regressão linear simples do Lucro Líquido e da Receita Líquida da Botucatu Têxtil SA.

Tabela 2 - Resumo dos Resultados da Análise de Regressão Linear Simples do Lucro Líquido e da Receita Líquida

\begin{tabular}{|c|c|c|}
\hline \multicolumn{2}{|c|}{ Análise de Regressão Linear Simples do LL e RL } & Resultados \\
\hline \multirow{4}{*}{ BOTUCATU TÊXTIL SA } & Coeficiente de correlação r & 0,764 \\
\cline { 2 - 3 } & Teste F (ANOVA) & 23,869 \\
\cline { 2 - 3 } & Sig. (ANOVA) & 0,000 \\
\cline { 2 - 3 } & Constante & $-4959,381$ \\
\cline { 2 - 3 } & Coeficiente angular & 0,277 \\
\hline
\end{tabular}

Fonte: dados da pesquisa.

Por meio destes dados, e conhecendo a margem líquida média da empresa é possível estimar o percentual de Custos e Despesas Fixas e, desta forma, estimar o percentual de Custos e Despesas Variáveis, obtendo assim a estrutura de custos da Botucatu.

Aplicando o modelo proposto sobre os dados da Botucatu Têxtil AS, obtém-se a equação de regressão: $L L=-4959,381+0,277^{\star} R O L$. Os dados da empresa permitem estimar o percentual de custos e despesas fixas. Aplicando a equação 
Estrutura de Custos das Empresas do Setor de Vestuário Listadas na Bovespa: Utilização da Análise de Regressão Linear Adriana Kroenke, Ari Söthe, Jorge Eduardo Scarpin

(6) $\mathrm{CDF} \% \mathrm{ROL}=\beta-\mathrm{ML}$, tem-se: CDF\%ROL = 0,277-(-0,12327), logo CDF\%ROL = 0,40. Sabendo que a margem de contribuição é de 0,277 e CDF\%ROL é de 0,40, conclui-se que os CDV\%ROL é de 0,32.

Em seguida, efetuou-se a análise de regressão linear simples onde a variável dependente passou a ser o Resultado Operacional e a variável independente a Receita Líquida. Este teste foi realizado para verificar se existe diferença na estrutura de custos da empresa. Os dados obtidos são apresentados na Tabela 3.

Tabela 3 - Resumo dos Resultados da Análise de Regressão Linear Simples do Resultado Operacional e da Receita Líquida

\begin{tabular}{|c|c|c|}
\hline \multicolumn{2}{|c|}{ Análise de Regressão Linear Simples da RO e RL } & Resultados \\
\hline \multirow{4}{*}{ BOTUCATU TÊXTIL SA } & Coeficiente de correlação r & 0,767 \\
\cline { 2 - 3 } & Teste F (ANOVA) & 24,336 \\
\cline { 2 - 3 } & Sig. (ANOVA) & 0,000 \\
\cline { 2 - 3 } & Constante & $-4962,856$ \\
\cline { 2 - 3 } & Coeficiente angular & 0,280 \\
\hline
\end{tabular}

Fonte: dados da pesquisa.

Aplicando a análise de regressão linear simples obteve-se a seguinte equação de regressão: $R O=-4962,856+0,280^{\star} R L$. De posse dos dados da empresa é possível estimar 0 percentual de custos e despesas fixas aplicando a equação (6) $\mathrm{CDF} \% \mathrm{ROL}=\beta-\mathrm{ML}$, onde: $\mathrm{CDF} \% \mathrm{ROL}=0,280-(-0,12327)$, logo $\mathrm{CDF} \% \mathrm{ROL}=0,40$. Sabendo que a margem de contribuição é de 0,280 e CDF\%ROL é de 0,40, conclui-se que os CDV\%ROL é de 0,32.

Analisando os resultados provenientes dos dois testes é possível verificar que não houve alteração na estrutura de custos da Botucatu. O percentual de CDF\%ROL e CDV\%ROL é igual nos dois casos.

\subsection{Cia Hering}

Com o objetivo de estimar a estrutura de custos da empresa realizou-se, primeiramente, a aplicação da análise de regressão linear simples da relação entre o Lucro Líquido e a Receita Líquida da empresa, considerando o Lucro Líquido (LL) como 
Estrutura de Custos das Empresas do Setor de Vestuário Listadas na Bovespa: Utilização da Análise de Regressão Linear Adriana Kroenke, Ari Söthe, Jorge Eduardo Scarpin

variável dependente e a Receita Líquida $(R L)$ como variável independente. Os dados obtidos são apresentados na Tabela 4.

Tabela 4 - Resumo dos Resultados da Análise de Regressão Linear Simples do Lucro Líquido e da Receita Líquida

\begin{tabular}{|l|c|c|}
\hline \multirow{4}{*}{ CIA HERING } & Coeficiente de correlação r & 0,265 \\
\cline { 2 - 3 } & Teste F (ANOVA) & 1,288 \\
\cline { 2 - 3 } & Sig. (ANOVA) & 0,272 \\
\cline { 2 - 3 } & Constante & $-17787,7$ \\
\cline { 2 - 3 } & Coeficiente angular & 0,244 \\
\hline
\end{tabular}

Fonte: dados da pesquisa.

Na Cia Hering não é possível estimar a relação entre Lucro Líquido e Receita Líquida visto que o teste $\mathrm{F}$ (ANOVA) apresentou uma significância superior a 0,05, 0 que indica que os coeficientes são todos iguais a zero.

A seguir também foi aplicada a análise de regressão linear simples com 0 Resultado Operacional como variável dependente e a Receita Líquida como variável independente. Os resultados são apresentados na Tabela 5.

Tabela 5 - Resumo dos Resultados da Análise de Regressão Linear Simples do Resultado Operacional e da Receita Líquida

\begin{tabular}{|c|c|c|}
\hline \multirow{4}{*}{ CIA HERING } & Coeficiente de correlação $r$ & 0,221 \\
\cline { 2 - 3 } & Teste F (ANOVA) & 0,870 \\
\cline { 2 - 3 } & Sig. (ANOVA) & 0,364 \\
\cline { 2 - 3 } & Constante & $-13468,4$ \\
\cline { 2 - 3 } & Coeficiente angular & 0,188 \\
\hline
\end{tabular}

Fonte: dados da pesquisa.

Considerando que o teste $\mathrm{F}$ (ANOVA) apresentou uma significância de 0,870, não é possível estimar a relação entre Resultado Operacional e Receita Líquida, visto que com a significância superior a 0,05 os coeficientes são todos iguais a zero.

\subsection{Marisol S/A}

A estrutura de custos da Marisol SA foi estimada por meio da análise de regressão linear simples considerando o Lucro Líquido como variável dependente e a 
Estrutura de Custos das Empresas do Setor de Vestuário Listadas na Bovespa: Utilização da Análise de Regressão Linear Adriana Kroenke, Ari Söthe, Jorge Eduardo Scarpin

Receita Líquida como variável independente. Os resultados deste teste são apresentados na Tabela 6.

Tabela 6 - Resumo dos Resultados da Análise de Regressão Linear Simples do Lucro Líquido e da Receita Líquida

\begin{tabular}{|l|c|c|}
\hline \multirow{4}{*}{ MARISOL SA } & Coeficiente de correlação r & 0,559 \\
\cline { 2 - 3 } & Teste F (ANOVA) & 7,737 \\
\cline { 2 - 3 } & Sig. (ANOVA) & 0,013 \\
\cline { 2 - 3 } & Constante & $-17360,2$ \\
\cline { 2 - 3 } & Coeficiente angular & 0,285 \\
\hline
\end{tabular}

Fonte: dados da pesquisa.

Com a aplicação da análise de regressão simples nos dados da Marisol SA obteve-se a seguinte equação de regressão: $L L=-17360,2+0,285^{\star} R L$. Analisando os dados, verifica-se que é possível obter a estimativa do percentual de custos e despesas fixas aplicando a equação (6) $\mathrm{CDF} \% \mathrm{ROL}=\beta-\mathrm{ML}$. Assim, $\mathrm{CDF} \% \mathrm{ROL}=0,285$ 0,076952, logo CDF\%ROL $=0,21$. Como a margem de contribuição é de 0,285 e CDF\%ROL é de 0,21, tem-se o valor de 0,51 para CDV\%ROL.

Tabela 7 - Resumo dos Resultados da Análise de Regressão Linear Simples do Resultado Operacional e da Receita Líquida

\begin{tabular}{|l|c|c|}
\hline \multirow{4}{*}{ MARISOL SA } & Coeficiente de correlação $r$ & 0,352 \\
\cline { 2 - 3 } & Teste F (ANOVA) & 2,402 \\
\cline { 2 - 3 } & Sig. (ANOVA) & 0,140 \\
\cline { 2 - 3 } & Constante & $-19583,0$ \\
\cline { 2 - 3 } & Coeficiente angular & 0,260 \\
\hline
\end{tabular}

Fonte: dados da pesquisa.

Considerando o Resultado Operacional como variável dependente e a Receita Líquida como variável independente não foi possível estimar a relação entre eles pelo fato do teste $F$ (ANOVA) apresentar uma significância superior a 0,05 , indicando que os coeficientes são todos iguais a zero. 
Estrutura de Custos das Empresas do Setor de Vestuário Listadas na Bovespa: Utilização da Análise de Regressão Linear Adriana Kroenke, Ari Söthe, Jorge Eduardo Scarpin

\subsection{Cotejamento das Empresas Analisadas}

Na Figura 1 apresenta-se a estrutura de custos da Botucatu Têxtil S/A e Marisol S/A, nas quais foi possível estimar por meio dos testes realizados os custos e as despesas fixas, bem como os custos e despesas variáveis e a margem de contribuição.

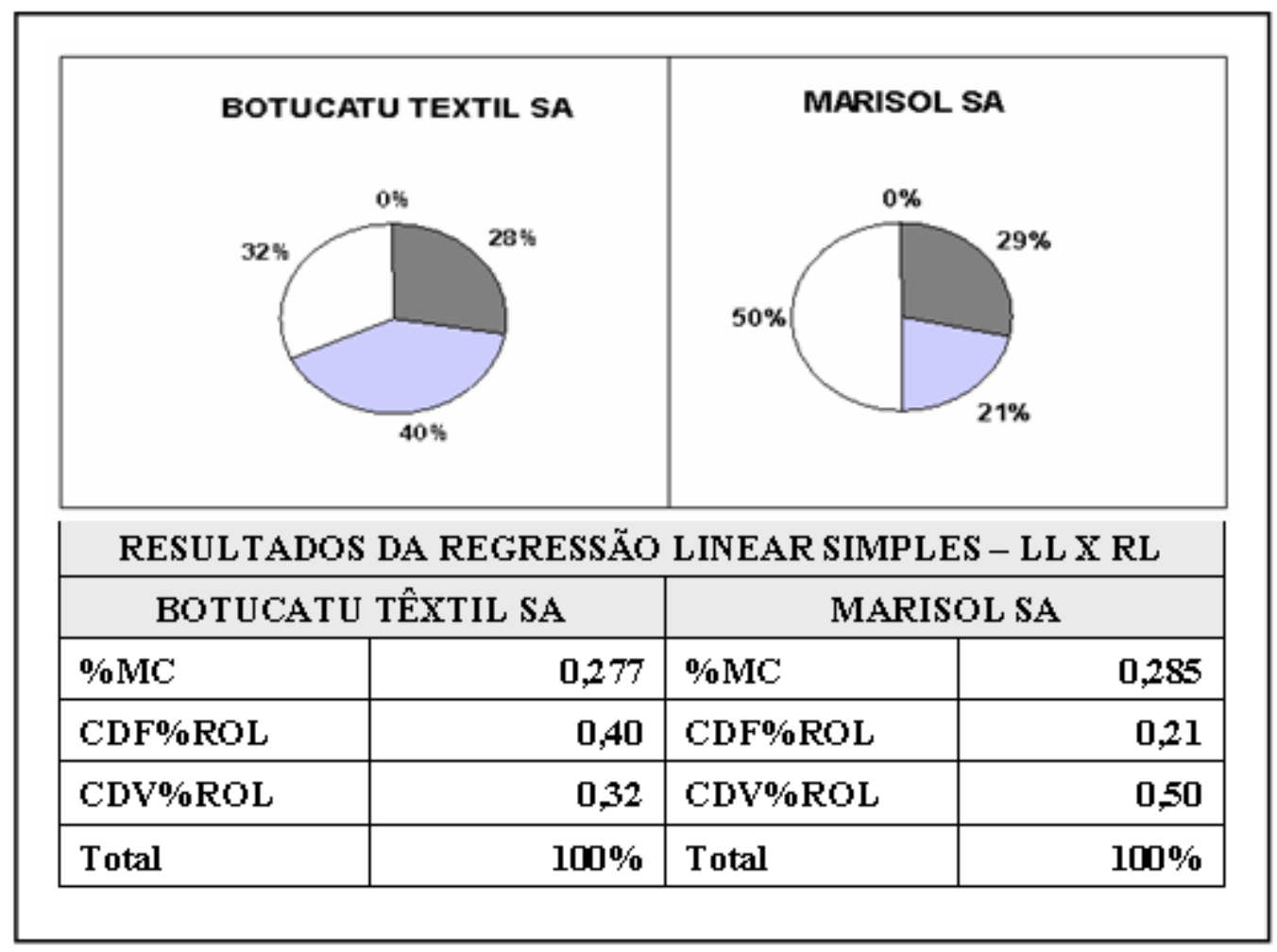

Figura 1: Estrutura de custos (Regressão linear Simples: LLxRL)

Fonte: dados da pesquisa

Constata-se por meio da Figura 1, que os percentuais das margens de contribuição das duas empresas são idênticos, no entanto, a estrutura de custos destas empresas é nitidamente oposta. Enquanto a Botucatu Têxtil SA possui custos e despesas variáveis reduzidos, além de custos e despesas fixas elevados, a situação se inverte na Marisol SA, onde os custos e despesas variáveis representam $50 \%$ da receita líquida da empresa e os custos e despesas fixas $21 \%$.

Infere-se que existe uma preocupação maior por parte da primeira empresa na diminuição dos seus custos e despesas variáveis, em relação aos custos e despesas fixas, otimizando assim a sua margem de contribuição. De outro modo, a Marisol SA, 
Estrutura de Custos das Empresas do Setor de Vestuário Listadas na Bovespa: Utilização da Análise de Regressão Linear Adriana Kroenke, Ari Söthe, Jorge Eduardo Scarpin

com um faturamento superior, preocupa-se na redução de seus custos e despesas fixas aumentando desta forma o seu lucro líquido.

Na Figura 2 é apresentada a estrutura de custos da Botucatu Têxtil SA na qual foi possível estimar, os custos e despesas fixas, custos e despesas variáveis e a margem de contribuição, considerando o resultado operacional como variável dependente.

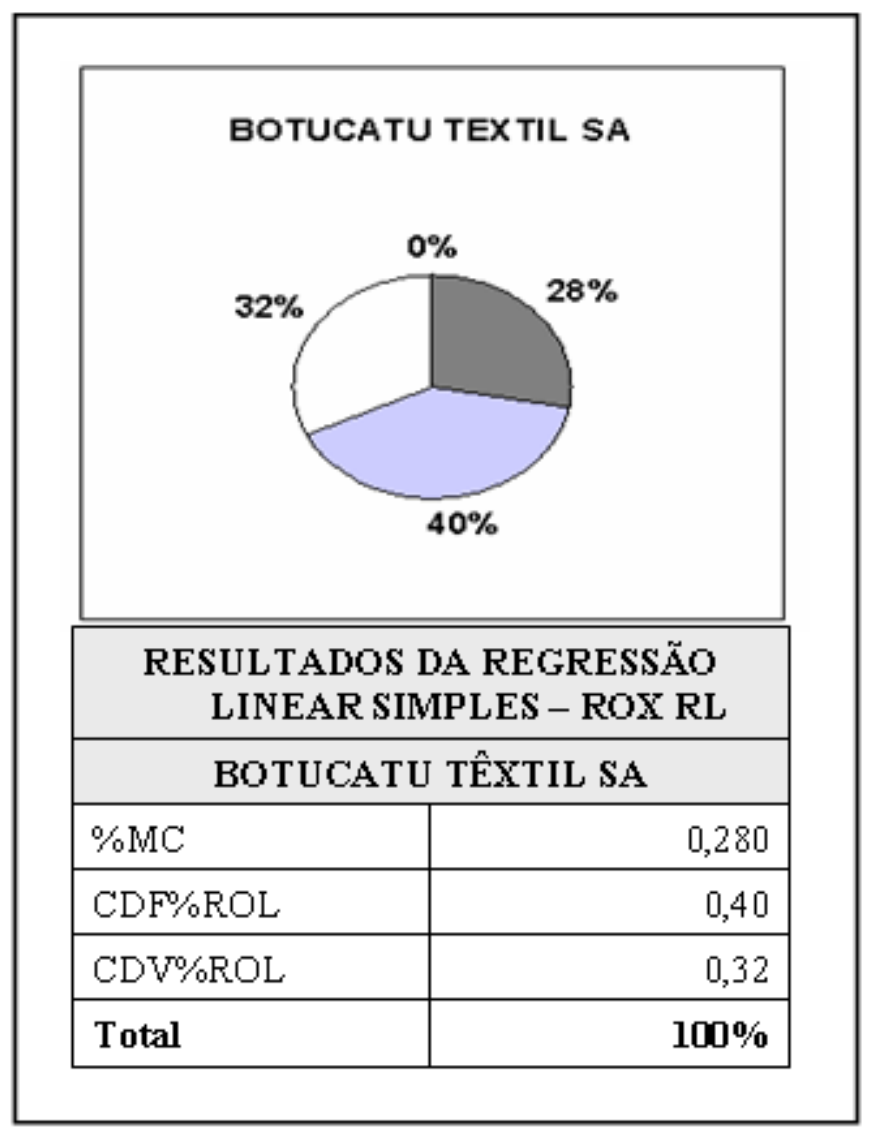

Figura 2: Estrutura de custos (Regressão Linear Simples: ROxRL) Fonte: dados da pesquisa

Se comparada com o teste onde a variável dependente foi o lucro líquido, apresentada na Figura 1, pode-se verificar que houve apenas uma pequena alteração na margem de contribuição, porém, nada significativo. Essa diferença se deve ao fato de que o lucro líquido considera os resultados não-operacionais caracterizados por elementos como, por exemplo, os ganhos e perdas na venda de ativos permanentes e 
Estrutura de Custos das Empresas do Setor de Vestuário Listadas na Bovespa: Utilização da Análise de Regressão Linear Adriana Kroenke, Ari Söthe, Jorge Eduardo Scarpin

resultados de controladas e coligadas. As provisões do imposto de renda e contribuição social, também são despesas que não incorporam o resultado operacional e são refletidos no lucro líquido do exercício. Neste caso, os resultados encontrados nas duas regressões da Botucatu Têxtil SA são idênticos pelos discretos resultados não operacionais e principalmente por apresentar constantes prejuízos líquidos nos exercícios, fazendo com que as provisões de imposto de renda e contribuição social fossem nulas.

\section{CONCLUSÃO}

Resgatando o objetivo geral deste estudo de verificar a estrutura de custos das empresas do setor de vestuário listadas na Bovespa, com a utilização da análise de regressão, buscou-se responder a seguinte indagação: Qual a estrutura de custos das empresas do setor de vestuário listadas na Bovespa? Assim, após a realização dos testes estatísticos nas empresas Botucatu Têxtil SA, Cia. Hering e Marisol SA, foi possível constatar que:

- Na Botucatu Têxtil SA, foram realizados os dois testes de regressão para estimar a estrutura de custos da empresa e constatou-se que não houve alteração no percentual de CDF\%ROL e CDV\%ROL, ou seja, os valores são iguais nos dois casos. Houve alteração somente na margem de contribuição, com um pequeno aumento, porém esta diferença não chega a ser significativa. Isso se deve ao fato de que o resultado não operacional e provisões de imposto de renda e contribuição social foram insignificantes e não refletiram nos resultados dos testes;

- Na Cia Hering não foi possível estimar a relação entre Lucro Líquido e Receita Líquida nem a relação entre Resultado Operacional e Receita Líquida visto que o teste $F$ (ANOVA) apresentou uma significância superior a 0,05 , indicando que os coeficientes são todos iguais a zero; e

- Na Marisol SA foi possível estimar a estrutura de custos aplicando análise de regressão linear considerando o Lucro Líquido como variável 
Estrutura de Custos das Empresas do Setor de Vestuário Listadas na Bovespa: Utilização da Análise de Regressão Linear Adriana Kroenke, Ari Söthe, Jorge Eduardo Scarpin

dependente e a Receita Líquida como variável independente. No caso da relação entre Resultado Operacional e Receita Líquida não foi possível estimar a estrutura de custos em função da significância apresentada pelo teste $F(A N O V A)$.

Por fim, verifica-se que a estrutura de custos da Botucatu Têxtil SA e Marisol SA apresentam diferenças consideráveis no percentual de custos e despesas fixas e no percentual de custos e despesas variáveis. Enquanto a Botucatu Têxtil SA apresenta custos e despesas fixas superiores e custos e despesas variáveis inferiores, a Marisol SA apresenta custos e despesas variáveis superiores aos custos e despesas fixas. A margem de contribuição das empresas não apresenta diferença significativa. Dessa maneira, conclui-se que apesar das três empresas analisadas serem do mesmo ramo e de capital aberto, a estrutura de custos apresenta uma diferença considerável nos custos e despesas fixas e custos e despesas variáveis.

\section{REFERÊNCIAS}

ALBANEZ, T. et al. (2007). Uma análise da estrutura de custos do setor sucroalcooleiro brasileiro. In: Congresso Brasileiro de Custos, 14. João Pessoa. Anais... Paraíba. CD ROM.

BEUREN, I.M. (2006). Como elaborar trabalhos monográficos em contabilidade: teoria e prática. (3 ed.). São Paulo: Atlas, 195 p.

CUNHA, J.V.A.; C.A.C. (2007). Regressão Linear Múltipla. In: CORRAR, Luiz J.; PAULO, Edílson; DIAS FILHO (Coord). Análise Multivariada: para os cursos de Administração, Ciências Contábeis e Economia. São Paulo: Atlas.

DIEHL, C.A. et al. (2008). Custeio Baseado em Atividades (ABC): um estudo sobre publicações em eventos científicos. In: ENANPAD, 32. Rio de Janeiro. Anais... Rio de Janeiro: ANPAD. CD ROM.

GARRISON, R.H e NOREEN, E. W. (2001). Contabilidade gerencial. (9 ed.). Rio de Janeiro: LTC, $643 \mathrm{p}$.

GOULARTI FILHO, A. e JENOVEVA NETO, R. (1997). A indústria do vestuário: economia, estética e tecnologia. Florianópolis: Letras Contemporâneas, 197 p. 
GORINI, A.P.F. (2000). Panorama do setor têxtil no Brasil e no mundo: reestruturação e perspectivas. BNDES Setorial, Rio de Janeiro. Disponível em: <http://www.bndes.gov.br/conhecimento/bnset/set1202.pdf>. Acesso em: 17/set/2008.

HAIR, J.F. (2005). Análise multivariada de dados. Traduzido por Adonai Schlup Sant'Anna e Anselmo Chaves Neto. (5 ed.). Porto Alegre: Bookman, 593 p.

HALL, R.J. et al. (2008). A utilização das ferramentas contábeis para tomada de decisão: um estudo nas micro e pequenas empresas do ramo de vestuário de Dourados - MS. Disponível em: www.admpg.com.br. Acesso em: 19/set/2008.

HANSEN, D.R. e MOWEN, M.M. (2001). Gestão de Custos. Tradução Robert Brian Taylor. (1 ed.). São Paulo: Pioneira Thomson Learning, 783 p.

HORNGREN. et al. (2000). Contabilidade de custos. (9 ed.). Rio de Janeiro: LCT.

KASPCZAK, M.C.M. e SCANDELARI, L. (2008). Um estudo exploratório sobre a utilização das informações de custos em indústrias de confecções na cidade de ponta grossa. Journal of Technology Management \& Innovation. vol. 2, 2007. Disponível em: $<$ www.jotmi.org $>$. Acesso em 18/set/2008.

LIMA, J.C. (2008). Novas formas, velhos conteúdos: diversidade produtiva e emprego precário na indústria do vestuário. Revista Política e Trabalho (15). João Pessoa, PB, setembro, 1999. Disponível em: <www.fundaj.gov.br>. Acesso em: 19/set/2008.

MAHER, M. (2001). Contabilidade de Custos: criando valor para a administração. Tradução José Evaristo dos Santos. São Paulo: Atlas.

MARTINS, E. (2003). Contabilidade de Custos. (9 ed.). São Paulo: Atlas.

OLIVEIRA, P.H.D. et al. (2006). Análise empírica do impacto da implementação do eticketing pelas companhias aéreas sobre o custo dos serviços prestados: o caso Tam S.A. In: Congresso Brasileiro de Custos, 13. Belo Horizonte. Anais... Minas Gerais. CD ROM.

RAUPP, F.M. BEUREN, I.M. (2004). Caracterização da Pesquisa em Contabilidade. In. BEUREN, I. M. (Org). Como elaborar trabalhos monográficos em contabilidade: teoria e prática. (2 ed.). São Paulo: Atlas.

ROLIM, C.F.C. (2008). Efeitos regionais de abertura comercial sobre a cadeia produtiva do algodão, têxtil, vestuário: uma versão resumida. Disponível em: <www.economia.ufpr.br>. Acesso em: 19/set/2008. 
SOARES, M.A. et al. (2007). Utilização da Programação Linear no Ensino da Contabilidade de Custos: uma comparação com as práticas tradicionais. In: Congresso Brasileiro de Custos, 14. João Pessoa. Anais... Paraíba. CD ROM.

STOFFEL, J.G. (2007). A importância do controle de custos nas pequenas empresas: um estudo aplicado a pequenas fábricas de confecções. In: Congresso Brasileiro de Custos, 14. João Pessoa. Anais...Paraíba. CD ROM.

STRUMIELLO, L.D.P. (1999). Proposta para o planejamento e controle da produção e custos para pequenas empresas do vestuário. 180f. (Dissertação de Mestrado). Universidade Federal de Santa Catarina - UFSC, 180 p.

WARREN, C.S. et al. (2003). Contabilidade Gerencial. (6 ed.). São Paulo: Pioneira Thomson Learning. 